\title{
Erratum to: PRISM II: an open-label study to assess effectiveness of dextromethorphan/ quinidine for pseudobulbar affect in patients with dementia, stroke or traumatic brain injury
}

Flora M. Hammond ${ }^{1 *}$, David N. Alexander ${ }^{2}$, Andrew J. Cutler ${ }^{3}$, Stephen D'Amico ${ }^{4}$, Rachelle S. Doody ${ }^{5}$, William Sauve ${ }^{6}$, Richard D. Zorowitz', Charles S. Davis ${ }^{8}$, Paul Shin ${ }^{9}$, Fred Ledon ${ }^{9}$, Charles Yonan ${ }^{9}$, Andrea E. Formella ${ }^{9}$ and Joao Siffert ${ }^{9}$

\section{Erratum}

After publication of the original article [1], the authors noticed that there were errors in the caption of Fig. 3, and the y-axis of Fig. 6 itself.

The following statement should not have been included in the caption of Fig. 3: "CNS-LS scores were not normalized." The CNS-LS is a rank-order scale, and is not normalized. This statement was included erroneously and the authors intended on removing it prior to resubmission, but this was unfortunately overlooked.

Similarly, the y-axis within Fig. 6 was mislabelled. The CNS-LS scale ranges from 7 to 35 , so the $y$-axis for Fig. 6 should start at a base score of 7 and not zero. The correct and updated version of Fig. 6, in which the data presented remain accurate and are unchanged, is published in this erratum.

\begin{abstract}
Author details
'Physical Medicine and Rehabilitation, Indiana University School of Medicine, Rehabilitation Hospital of Indiana, 4141 Shore Drive, Indianapolis, IN 46254, USA. ${ }^{2}$ University of California, Los Angeles, CA, USA. ${ }^{3}$ Florida Clinical Research Center, LLC, Bradenton, FL, USA. ${ }^{4}$ Cornerstone Medical Group, Franklin, TN, USA. ${ }^{5}$ Baylor College of Medicine, Houston, TX, USA. ${ }^{6}$ TMS NeuroHealth Centers, Richmond, VA, USA. ${ }^{7}$ MedStar National Rehabilitation Network, Washington, DC, USA. ${ }^{8}$ CSD Biostatistics, Inc., Tucson, AZ, USA. ${ }^{9}$ Avanir Pharmaceuticals, Inc., Aliso Viejo, CA, USA.
\end{abstract}

Published online: 02 September 2016

\section{Reference}

1. Hammond FM, Alexander DN, Cutler AJ, D'Amico S, Doody RS, Sauve W, et al. PRISM II: an open-label study to assess effectiveness of dextromethorphan/quinidine for pseudobulbar affect in patients with dementia, stroke or traumatic brain injury. BMC Neurol. 2016;16:89. doi:10.1186/s12883-016-0609-0.

* Correspondence: Flora.hammond@rhin.com

${ }^{1}$ Physical Medicine and Rehabilitation, Indiana University School of Medicine, Rehabilitation Hospital of Indiana, 4141 Shore Drive, Indianapolis, IN 46254, USA 


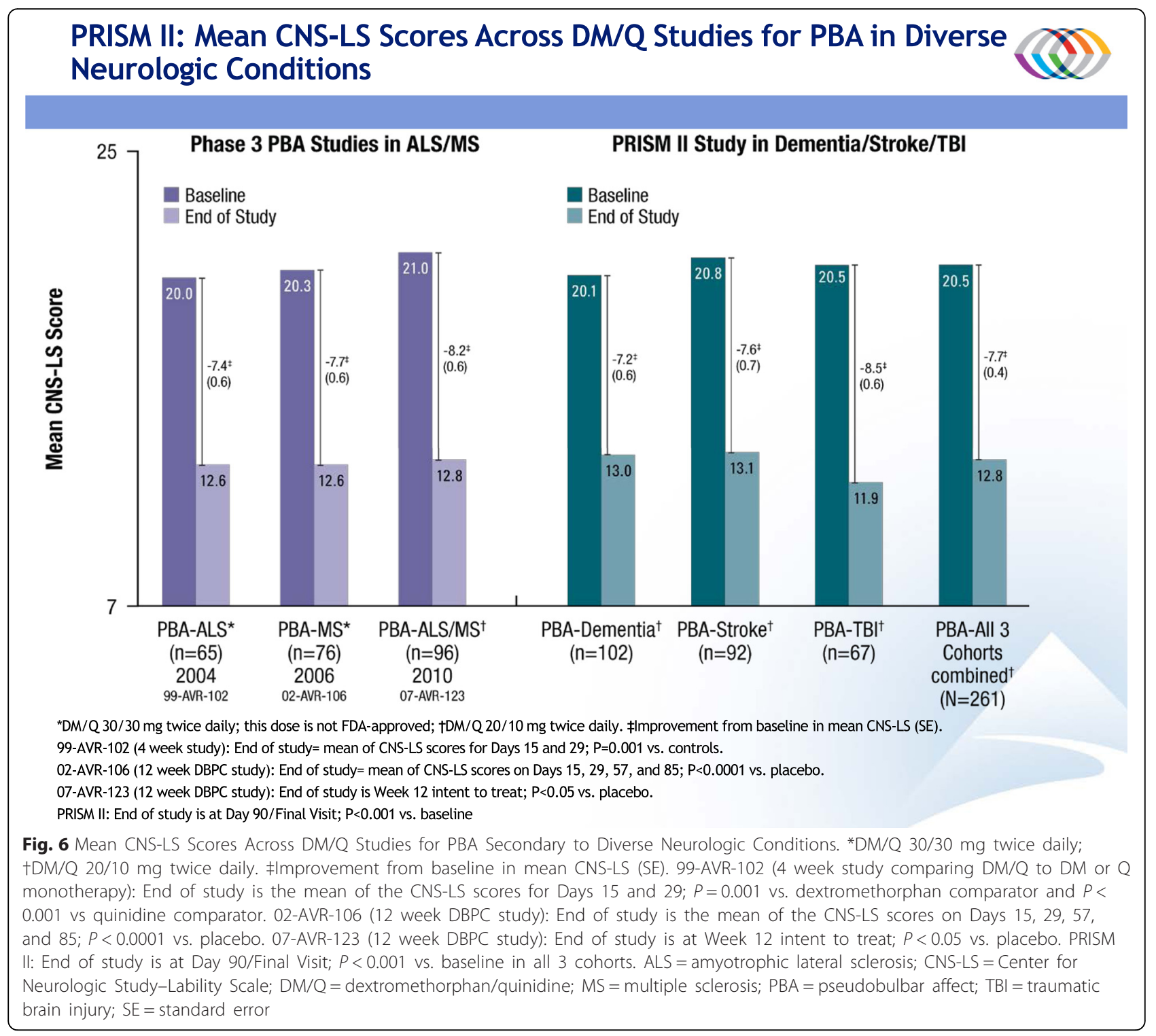

